\title{
SIMPLE SUPPORTED COMPOSITE BEAM - PREPARATION FOR DAMAGE ASSESSMENT
}

\author{
M. Venglár", M. Sokol ${ }^{* *}$, K. Lamperová ${ }^{* * *}$, M. Marföldi ${ }^{\dagger}$
}

\begin{abstract}
The paper is dedicated to some parts of structural health monitoring (SHM) using non-destructive vibration-based methods. An experimental model was made from two materials - wood and plasterboard. Supports could be alternatively considered, but the simply supported beam was considered in this research. Modal analysis was performed from recorded data (18 accelerometers along the experimental bridge in vertical direction and six sensors in horizontal directions). Two artificial exciters were used for harmonic excitation. The placement was asymmetrical. Dynamic characteristics as natural frequency, damping ratio and corresponding mode-shape were obtained using two methods (Discrete-Time Fourier Transform and stabilization charts using the Stochastic Subspace Identification method). Comparison of the methods was prepared. Some mode-shapes were processed for identification of the damage by application FE model updating method.
\end{abstract}

Keywords: composite beam, experimental testing, artificial excitation, DTFT, SSI

\section{Introduction}

Nowadays, the non-destructive testing (NDT) of civil structures achieves popularity among research teams (Bayer, 2017 and Ároch, 2016 or Zenunovic, 2015 or Kratochvil, 2014) because of increasing demands on safety and reduction of maintenance costs. Another reason is that many bridges are obsolete almost $40 \%$ of American bridges are 50 years old or older as it is mentioned in the Infrastructure report card 2017 published by the American Society of Civil Engineers (ASCE). In accordance the document, $10 \%$ of bridges is structurally deficient due to the lack of long-lasting maintenance or periodic inspections. It can sometimes result in a need of expensive renovation. Early damage detection can help to avoid mentioned situations and to increase structural health of bridge structures. Because of that, this paper is devoted to some stages of SHM of an experimental bridge model - the composite beam. Two ways were assumed for modal analysis: The Discrete-Time Fourier Transform (DTFT) and stabilization charts using Stochastic subspace identification (SSI) method. This technique has big advantage where the modal density becomes high due to close modes with high damping (Moller, 2014).

The experimental model of the bridge was made from three wooden planks and three plasterboards. The wooden boards were used for the main beam, and the bridge deck was made of three standard plasterboard layers of height $12.5 \mathrm{~mm}$. The deck was $300 \mathrm{~mm}$ wide and $37.5 \mathrm{~mm}$ high. The plasterboard layers were screwed every $170 \mathrm{~mm}$ into the main wooden beam. The cross-section of the experimental

\footnotetext{
Ing. Michal Venglár: Department of Structural Mechanics, Slovak University of Technology, Faculty of Civil Engineering, Radlinského 11; 810 05, Bratislava; SK, michal.venglar@stuba.sk

** Prof. Ing. Milan Sokol, PhD.: Department of Structural Mechanics, Slovak University of Technology, Faculty of Civil Engineering, Radlinského 11; 810 05, Bratislava; SK, milan.sokol@stuba.sk

*** Ing. Katarína Lamperová.: Department of Structural Mechanics, Slovak University of Technology, Radlinského 11; 810 05, Bratislava; SK, katarina.lamperova@stuba.sk

$\dagger \quad$ Ing. Monika Marföldi: Department of Structural Mechanics, Slovak University of Technology, Faculty of Civil Engineering, Radlinského 11; 810 05, Bratislava; SK, monika.marfoldi@stuba.sk
} 
model is shown in Fig. 1 a). The whole length of the model was four meters with joint supports, see Fig. 1 b).

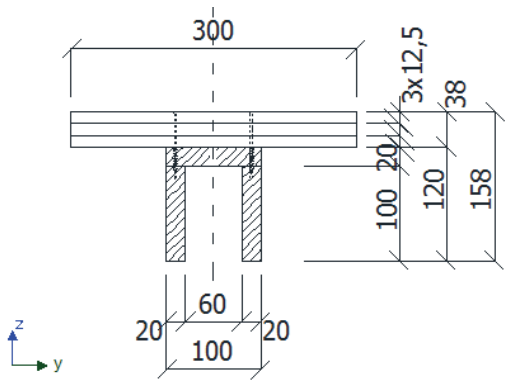

a)

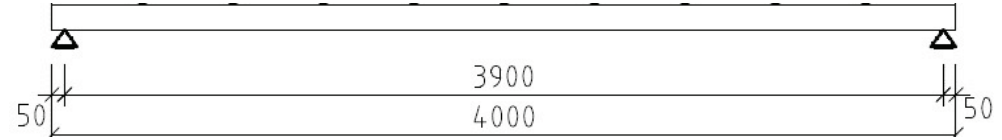

b)

Fig. 1: The experimental model a) Cross-section b) Side-view (dimensions in mm).

\section{Experimental testing}

Used National Instruments devices allowed us to measure up to 24 channels parallelly (Fig. 2). The NI 9234 modules allowed us to measure with the sampling rate of approximately 1651 samples per second for each channel. 19 sensors (mainly PCB Piezotronics 393B31 - black circle) were placed for a measurement of vertical accelerations. Five other MMF KS901.100 sensors were in operation during measurements in horizontal directions (marked as dashed circles). They were mounted on the structure using magnets.

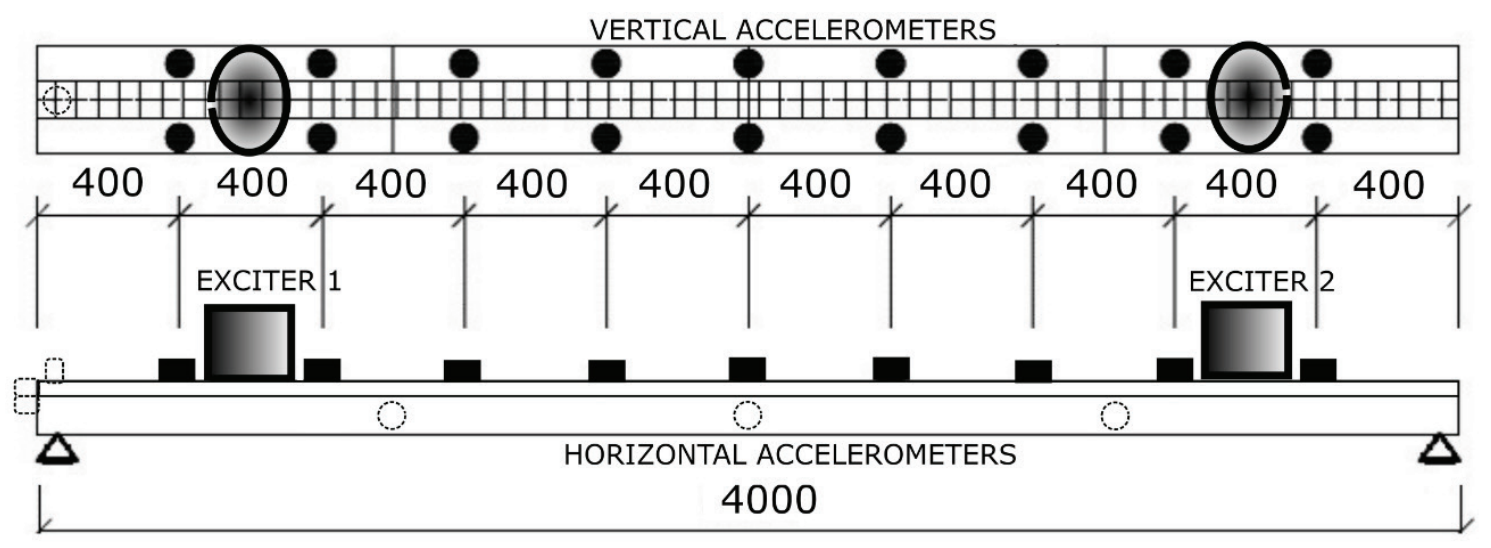

Fig. 2: The layout of accelerometers for measurements.

The harmonic vibrations in the frequencies of the following values $(11 \mathrm{~Hz}, 13 \mathrm{~Hz}, 15 \mathrm{~Hz}$ and $29 \mathrm{~Hz})$ were excited by two electromagnetic exciters with a moving mass of $0.6 \mathrm{~kg}$. Finally, four 10 -second data records were acquired, including the last five second period after stopping the exciter. Subsequently, this part was clipped for further analysis. Input signals were not measured. The layout of accelerometers in combination with exciters allowed us to identify with sufficient accuracy only some mode-shapes (the $1^{\text {st }}$, the $9^{\text {th }}$ and the $10^{\text {th }}$ frequency and its mode-shape).

\subsection{Discrete-Time Fourier Transform (DTFT)}

Very short data records were a reason why the DTFT was used for acquisition of dynamic parameters. Although, amplitude spectra using the Fast Fourier Transform (FFT) were also prepared. For example, Wang (2016) summarized advantages over the FFT method. The similar results are presented in Fig. 3. It shows response spectra computed using the DTFT in comparison to the FFT. Both were calculated from the time data no. 1. The DTFT gave more precise results because the FFT depends on the number of samples in the transform. In the case of clipped five second period, the frequency resolution was $0.2 \mathrm{~Hz}$. Whereas the DTFT resolution was assumed $0.005 \mathrm{~Hz}$. 


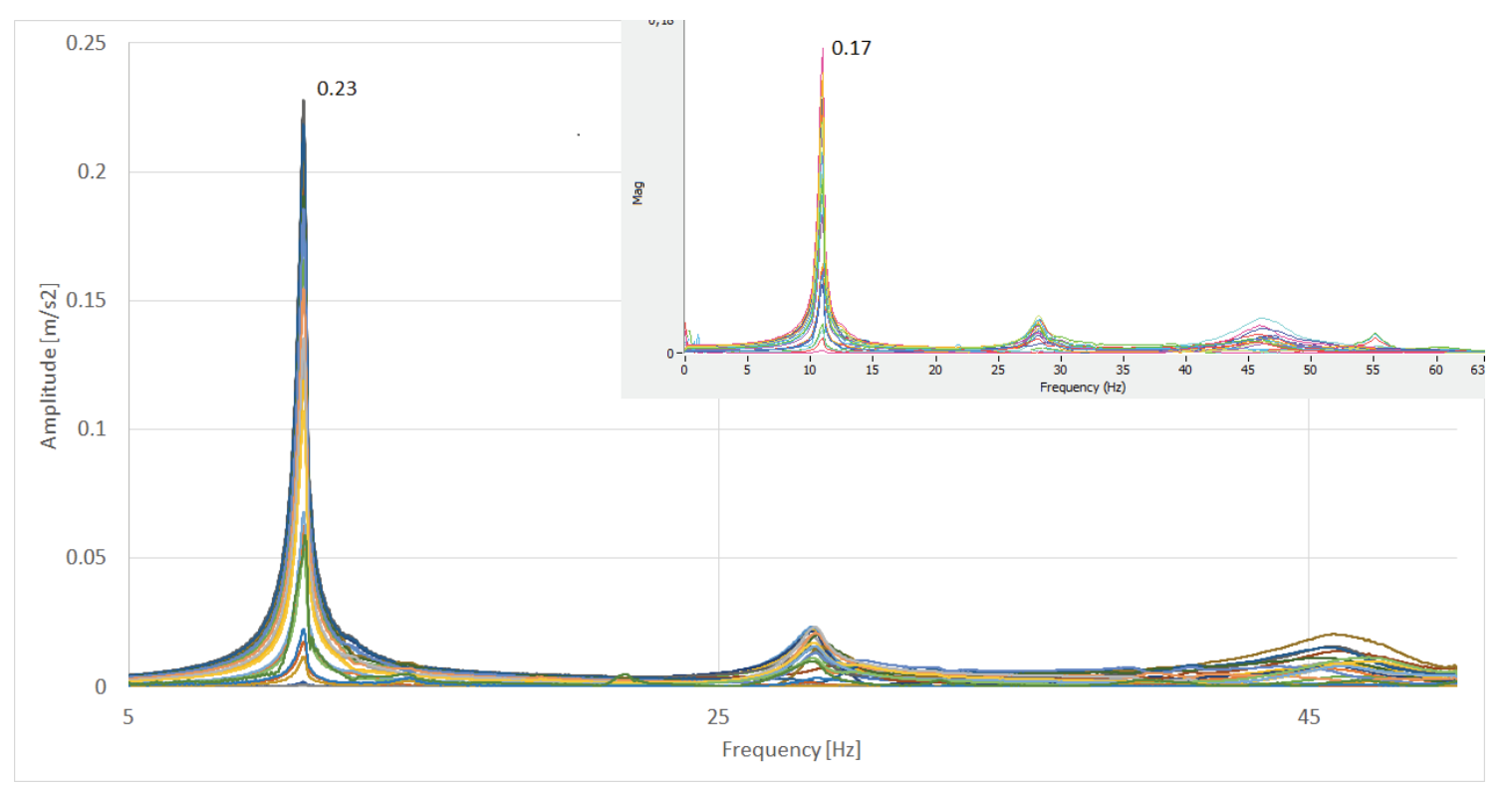

Fig. 3: Spectrum from the record no. 1 by using DTFT and FFT (smaller one).

\subsection{Stochastic subspace identification (SSI)}

The measured and pre-processed data were analysed in another way, using ModalVIEW software. Software possibilities (stabilization charts) were used for extracting modal parameters as natural frequency, damping ratio and matching mode-shape. Stabilization charts were calculated using the Stochastic Subspace Identification (SSI) method. The method is suitable when input signals are unmeasured or cannot be measured (Peeters, 2000) and only output data are available. In this case, stability criteria were chosen according to Lau (2007). The assumed values were $1 \%$ for frequency stability, $5 \%$ for damping stability and $2 \%$ for eigenvector stability. In accordance with mentioned criteria, some mode-shapes and their natural frequencies and damping ratios were extracted (Fig. 4). The $1^{\text {st }}$ mode-shape represents vibration in Z-direction. The $9^{\text {th }}$ natural frequency is associated to the $3^{\text {rd }}$ vertical mode-shape. The $3^{\text {rd }}$ torsional mode-shape (the $10^{\text {th }}$ natural frequency) was also extracted.

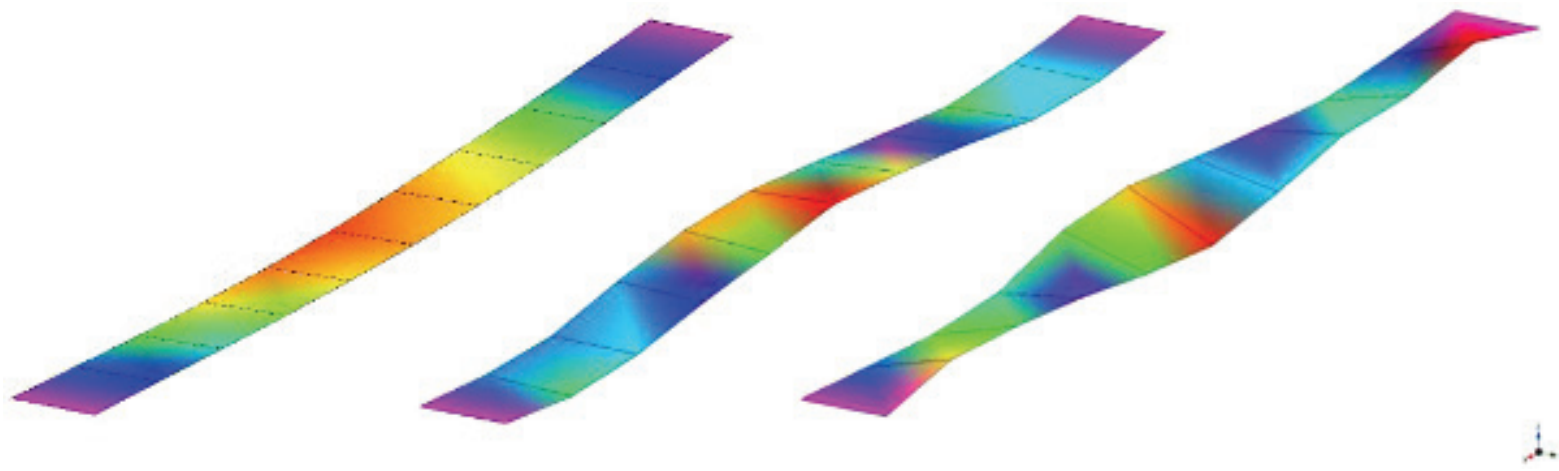

a)

b)

c)

Fig. 4: Extracted model parameters by ModalVIEW (using SSI method) a) the $1^{\text {st }}$ mode-shape b) the $9^{\text {th }}$ mode-shape c) $10^{\text {th }}$ mode-shape.

\section{Comparison of achieved results}

Natural frequencies and damping ratios were compared in this chapter. Damping ratio was calculated for the 1 st mode-shape. The damping ratio from SSI method equalled to $0.814 \%$ and damping ratio calculated from the spectrum prepared by the DTFT was $0.915 \%$. The damping ratio for the 9th modeshape from SSI method was equalled to $3.706 \%$ and damping ratio calculated from spectra was $4.344 \%$. The damping ratio was also calculated for the 10th mode-shape. SSI method equalled to $2.137 \%$ and damping ratio calculated by the DTFT was $3.508 \%$. Damping ratios could also be calculated from time 
series, but now they were not determined in that way. The natural frequencies are compared in the following tables (Tab. 1), obtained by the DTFT and by stabilization charts using the SSI method.

Tab. 1: Comparison of the $1^{\text {st }}$ measured frequency (in $\mathrm{Hz}$ ).

\begin{tabular}{ccccccccc}
\hline \multicolumn{2}{c}{ The $\mathbf{1}^{\text {st }}$ frequency } & \multicolumn{3}{c}{ The $^{\text {th }}$ frequency } & \multicolumn{3}{c}{ The 10 ${ }^{\text {th }}$ frequency } \\
\hline No. of record & DTFT & SSI & No. of record & DTFT & SSI & No. of record & DTFT & SSI \\
\hline 1 & 10.93 & 10.85 & 1 & 45.83 & 45.83 & 1 & 47.02 & 46.95 \\
\hline 2 & 11.00 & 10.97 & 2 & 46.67 & 46.83 & 2 & 47.73 & 47.60 \\
\hline 3 & 10.98 & 10.97 & 3 & 45.15 & 45.14 & 3 & 47.23 & 46.74 \\
\hline 4 & 11.00 & 10.97 & 4 & 45.99 & 45.88 & 4 & 46.51 & 46.12 \\
\hline
\end{tabular}

\section{Conclusions}

Three natural frequencies (the $1^{\text {st }}$, the $9^{\text {th }}$ and the $10^{\text {th }}$ frequency) obtained by two different methods were compared in this paper. Stabilization charts using the SSI method calculated comparable mode-shapes and other dynamic parameters to the spectrum by the DTFT. The difference in the $1^{\text {st }}$ mode-shape and corresponding natural frequency was negligible. Another advantage of the SSI method, besides the input signal can be unknown, is that mode-shapes are extracted directly. Thanks to that, the results can be used for damage detection as in Sokol (2017). Other compared natural frequencies were less accurate because of the higher number of the identified mode-shapes. The number of used sensors for the higher modeshapes was on the edge of possibilities. The next research could also be prepared with measured input signals for even better results.

\section{Acknowledgement}

This paper has been supported by the Slovak Research and Development Agency (SRDA) - grant from research program No. APVV-0236-12 and it was also created with the support of the Ministry of Education, Science, Research and Sport of the Slovak Republic within the Research and Development Operational Program for the project "University Science Park of STU Bratislava", ITMS 26240220084.

\section{References}

Ároch, R., Sokol, M. and Venglár, M. (2016) Structural Health Monitoring of Major Danube Bridges in Bratislava. Procedia Engineering, 156, pp. 24-31.

Bayer, J. (2017) Aa concept for testing and monitoring of building structures - theoretical case study, in: Engineering Mechanics 2017, Brno University of Technology, Brno, pp. 122-125.

Kratochvíl, O. and Križan, J. (2014) Analysis of dynamic response of footbridge Veveří on pedestrian load, in: Engineering Mechanics 2014, Brno University of Technology, Brno, pp. 56-84.

Lau, J., Lanslots, J., Peeters, B. and Van der Auweraer, H. (2007) Automatic modal analysis. Reality or myth?, in: Proc. Int. Modal Analysis Conf. 2007, 10 pp.

Moller, N., Gade, S. and Herlufsen, H. (2014) Stochastic Subspace Identification Technique in Operational Modal Analysis, in: 1st International Operational Modal Analysis Conference (IOMAC 2005), Curran Associates, New York, pp. 37-45.

Peeters, B. (2000) System Identification and Damage Detection in Civil Engineering. PhD Thesis, KU Leuven, Leuven.

Sokol, M. and Venglár M. (2017) System identification of a composite beam. Pollack Periodica, 2017, 12, 3, pp. 4354.

Zenunovic, D., Topalovic M. and Folic, R. (2015) Identification of Modal Parameters of Bridges Using Ambient Vibration Measurements. Shock and Vibration, 2015, pp. 1-21.

Wang, L., Lie, S.T. and Zhang, Y. (2016) Damage detection using frequency shift path. Mechanical Systems and Signal Processing, 66-67, pp. 298-313. 